\title{
Letting the Moment Take You: A Conversation with Alexander Billet
}

\author{
Interviewed by Greg Shupak
}

\begin{abstract}
Alexander Billet is a writer and music and arts critic based in Chicago. He is on the editorial board of Red Wedge magazine and has also contributed to Jacobin, New Politics, TheNation.com, and the Electronic Intifada. He can be reached through his Twitter. Earlier in 2014, Billet published an essay-length review of Yellow Power, Yellow Soul: The Radical Art of Fred Ho in Jacobin magazine, as well as an obituary of Ho, who died on April 12, 2014.
\end{abstract}

\section{Introduction}

Utopia, Erik Olin Wright informs us, "is a place in the imagination of peace and harmony, of flourishing lives and happiness; it is a fantasy world where our ideals of a just and good society are fully realized. Utopia reflects the human longing for escape from the oppressions, disappointments, and harsh realities of the real social world" (37). Wright's comments might ring equally true if we substitute each use of "utopia" with "art" or "music" or, most relevant for our context, "improvised jazz." The very act of imagining the type of world Wright describes is an act of art-making, a composing of that which does not yet exist set against that which does. As Alexander Billet says in the discussion that follows, art "can give us glimpses of a much more liberated way of life. It's only a glimpse, and it's a fractured glimpse at that, but it's still quite potent." My conversation with Billet is punctuated by such insights into the intersections between utopianism and creativity, particularly that which takes the form of improvised jazz.

While Billet's observations have much to offer studies of improvisation in general and of Fred Ho in particular, I am especially keen to highlight Billet's thoughts on the utopian dimension of this music, because I think that Billet's commentary is in its own right an important contribution to the nascent re-vamping of the radical imagination that has been underway since at least the turn of the twenty-first century. ${ }^{1}$ Consider, for instance, a distinction between Billet's comments on utopia and those that Wright puts forth. Wright emphasizes the importance of "elaborat[ing] clearheaded, rigorous, and viable alternatives to existing social institutions that both embody our deepest aspirations for human flourishing and take seriously the problem of practical design. Real utopias capture the spirit of utopia but remain attentive to what it takes to bring those aspirations to life" (37). For Wright, a "real utopia" is a concrete example of a utopian experiment that has actually been enacted with some success, such as the mass-exercise in radical democracy that takes place in Porte Alegre, Brazil when all residents of the city are invited to be part of the participatory budgeting process (38-40). These case studies are part of what Wright sees as the crucial task of "develop[ing] strategies that enable us to make empirically and theoretically sound arguments about emancipatory possibilities" (37). I do not want to imply that Wright dismisses the value of fanciful visionings of just societies or aspects of them; my point is that Billet resists a separation between the grounded utopias that Wright calls for and the uninhibited dreaming that often characterizes utopianism. Billet argues that "we can and should theorize and be materialist in our assessments, and take our education seriously. But at a certain point, fighting for a better world has to take that leap into the imaginary precisely so that it can make fantasy into reality." It is misguided, Billet suggests, to privilege or attempt to bracket off the real-world exercises in utopia from the imaginative processes animating them.

One conclusion I draw from Billet's comments throughout this interview is that, despite or perhaps even because of the dimension of fantastical play at work in improvised jazz, performances of this music can be thought of as examples of real utopias. What I am suggesting is that one instance where utopia functionally (if fleetingly) exists in our decidedly un-utopian world is in those moments and spaces where improvised jazz is played. ${ }^{2}$ Wright argues that "What we want are utopian destinations which, even if they are themselves unreachable, nevertheless have accessible waystations that help move us in the right direction. Exploring real utopias implies developing a sociology of the possible, not just the actual" (37). Improvised jazz, Billet's remarks suggest, is one such waystation: "let the moment take you' so to speak,[. . . ] allowing yourself to go on an unpredictable riff-a riff that maybe even you have no idea how it will end up-that's when the utopia starts to come out. In that moment, you are both organically and seamlessly rooted in your aural surroundings and reinventing those surroundings on the fly. It's a freeing experience." That unhindered freedom, that capacity to re-make the world, is where improvised jazz performances can realize utopia-in fragments that form a part of Wright's sociology of the possible.

Perhaps no better example of the utopian character of improvised jazz can be found than in the late Fred Ho, who is the focus of much of my interview with Billet, and whose work has previously been featured in Critical Studies in Improvisation/Études critique en improvisation. As Billet says, art's utopian strength is that it allows us "to imagine and fantasize and strengthen the parts of our creativity that get systematically neglected and atrophied under capitalism. If that's all that Fred Ho leaves for us to learn from, then I think he will have left a safe and wonderful 
legacy. [ . . H] is sounds and compositions were attempts at creating a new logic fundamentally different from and subversive to what we're told."

\section{The Interview: Alexander Billet on Fred Ho and Radical Art in the Neoliberal Age $^{3}$}

Greg Shupak: In your obituary of Fred Ho, you describe him as "an artist who attempted to take on the contemporary stagnation of art under capitalism during an era decidedly hostile to such projects." Can you explain how Ho understood the relationship between "stagnant" art and capitalism?

Alexander Billet: Fred Ho collaborated and worked with so many people throughout his life and career and touched a lot of lives-unfortunately, I wasn't lucky enough to be one of them. There are a great many impressive thinkers and creators that I think could give a much more in-depth view on how he understood that relationship: Ann T. Greene, Magdalena Gomez, Bill Mullen, Salim Washington. I would definitely recommend your readers look at what some of these individuals have said about Fred Ho's work. My interest in the man and the artist springs from my own fascination with the intersection between art and radical struggle. What Ho had to say was some of the most cogent and creative thinking l've seen regarding that relationship. There were a great many 20th century radical thinkers who illuminated art's social function-Bertolt Brecht, Walter Benjamin, Ernst Fischer, many others. I'd say Ho definitely followed in their footsteps, but was very practical about it. By that I don't mean he was pragmatic-he was quite utopian in fact, and in the best sense. I mean he sought to put the contours of art and politics into actual practice, and he was very concerned with grasping those contours in a contemporary context.

And so, when it comes to how capitalism stagnates art, I think there are a lot of things that have to be taken into consideration vis-à-vis Fred Ho. Very straightforwardly, he understood the interaction between capitalism and art as a Marxist would be expected to. Naturally, there's the suspicion of the music and culture industries, or at least an acknowledgement of what those industries do to culture in their endeavor to be profitable-straightforward commodification of music, etc. He was normally quite disparaging in the way he would speak about the sanitized, "Lincoln Center" version of jazz music that predominates today and totally denies its radical aesthetics of the 30 s and 60s.

There's more to it than that, however: a more holistic and well-rounded way of looking at art in the context of class society. Ho sought to understand and undermine through his work the way in which art has been fractured, segregated, and compartmentalized in our daily lives. Tamara Roberts, in her introduction to Yellow Power, Yellow Soul, describes Ho's creative philosophy as "one in which art and politics do not merely reflect, but constitute one another." It's a rather heady way to regard the relationship between the two, but if you think about it, it makes sense. Art and politics operate on separate planes today, but they remain interconnected. Furthermore, the division between them should be regarded as an outcome of the way that human labor has been divided and broken down and alienated over time, particularly since the dawn of capitalism several hundred years ago. This idea that art and politics can "constitute each other" is one that tries to bridge that separation, to make politics a realm of creativity once again. This is, naturally, quite opposed to how politics are thought of by most people today, which is as something done by an elite few making decisions for the rest of us, and certainly seems to have little to do with creativity.

Trying to bridge this gap through art brings with it all sorts of impossibilities, but it can certainly make for interesting art. When you see the sounds you integrate in your music as upsetting a colonial consciousness in the listener, it raises a whole slew of very challenging questions not only related to whether the songs are successful, but what it means for those songs to be successful. The willingness to open up all of these kinds of quandaries is something we rarely see in music, and l'd argue that ultimately this can be traced to the kind of alienation it has to endure along with every other kind of creativity under capitalism.

GS: You write that Ho embodied "the relentless creativity that can come when we resist with every atom of our being." Can you tell us more about what Ho thought of how resistance fosters creativity? What do you think of that relationship?

AB: I think the most illustrative example of how Ho thought of creativity and resistance is to be seen with how he dealt with his cancer diagnosis. If you read Diary of a Radical Cancer Warrior, you see that from the moment he was diagnosed, he saw himself as in resistance-not just against the cancer itself, but against what it represented. With all the toxins and chemicals that capitalism has thrown into our daily lives-the air, our food, our water, the everyday objects we interact with-is it any wonder that so many diseases like cancer thrive? So for him the battle against cancer was basically his own war against capitalism. 
And if you look at the amount of work he produced in the seven years between his diagnosis and his death, it's rather hard to deny that this battle itself unleashed something deep and stunning. In 2010, three years after his diagnosis, right around the time he turned his back on allopathic medicine, ${ }^{4}$ Ho claimed to people that he had basically died and been reborn. Of course he was speaking metaphorically, but during the last four years, the work produced by this "new Fred Ho," the Fred Ho that was "resisting with every atom" if you will, was just incredible. Those last years were probably his most prolific. At an event in Amherst about year before he died, he claimed that even though his body wasn't as strong and his abilities on the saxophone had diminished, he was at a creative peak.

There's of course another, more strictly political dimension to this. Ho, as a Chinese-American, the son of immigrants, someone who experienced racism first-hand, saw the incorporation of non-western genres into one's musical palette as being a form of resistance. This isn't to be taken lightly, particularly in today's age with this condescending notion of "world music" bearing such hegemony over how western listeners will hear classical and folk compositions from China, Indonesia, Ghana, Pakistan, and so on. Ho's mixture of this into a jazz ethos-and we should be careful when we use the term "jazz" to describe Ho's music; he understandably views the label as a way to segment off the contribution of Black and African classical music from music as a whole-was really very uniquely executed. He would allow the elements of each to play off each other, fight it out before seamlessly blending into one and the same. This is a refreshingly irreverent way to view music of non-western countries. You listen to the way that western curators will talk about and present this music to an audience, and it almost comes off as if they're trying to preserve the music in formaldehyde, to make it into a static thing to be observed rather than engaged with. Ho's approach was just the opposite-nothing is sacred: everything is up for grabs in terms of expression, and respecting these sounds means giving them their own life and path.

Now, in a racist society, in a society that systematically either devalues or co-opts the cultures of non-white peoples, to have an approach that views music of the "Third World" as both legitimate and fluid, as having its own autonomy and integrity and aesthetic evolution-that's an approach that can be quite revelatory for the listener. That aspect of Ho's work is one that pretty accurately captures what I think about the relationship between resistance and creativity. There are certain sounds and arrangements that we're told are bad or just don't work together. Well who said so? Who made the fucking rules? When we take hitherto divergent aesthetics and make them work together in an intelligent and thoughtful way, then we loosen up the audience's thinking and potentially can create alternative narratives. That's what made a movement like the Surrealists so controversial for their own time and place: they took concepts that they were told "didn't work together" and put them together anyway. It was a deliberate middle finger to aesthetic convention, and that can often be accompanied by a similar questioning of other standards and mores. Ho's work is effective for a generally similar reason, but because there is an anti-capitalist and anti-racist dimension to it, there's a whole new dynamic of consciousness that gets pulled along.

GS: Part of your explanation of Ho's concept of "the popular avant-garde" is that Ho believed "that the avant-garde should not only be the purview of the elite," and you have written extensively on avant-garde music yourself. Do you find that the avant-garde scene in late capitalist society is primarily made up of people who, despite their radical aesthetics, can be understood as part of a hegemonic class? Did Ho find this to be the political position of many he encountered in the avant-garde world?

AB: Is today's avant-garde part of a class? No, at least not in the way I understand the category of class, which is the Marxian way. And they certainly aren't hegemonic. Let me clarify what I mean when I say that the avant-garde has become the purview of the elite. Generally, when you're trying to consciously create an aesthetic that runs counter to ruling ideas of society, you by necessity are starting out in a minority. This is true for any ideological expression, not just aesthetics. You may or may not want to grow into a bigger force that can vie for influence. A great many avantgarde movements have had no interest in "reaching the masses" as it were, but some have grappled with what that might mean. One way or the other, whether you think you can convince others or not, you're rejecting the way that most people think. So I don't find it controversial to say that being part of an artistic avant-garde can bring with it all kinds of trappings that we would call elitist. There's a difference between that and the avant-garde being "the purview of the elite," however.

One of the processes that has uprooted the avant-garde and almost entirely banned it to the halls of academia has been capitalism's rather cynical embrace of much of what the avant-garde has done at one time or another. In the years following the Russian Revolution, there were huge numbers of artists from various experimental schools that looked to revamp the aesthetics of every facet in Russian society. There were all sorts of noble and exciting ideas that came along with that mission: the working class deserve beauty in their lives, the old aesthetics have been designed to keep us in our place and now we can reinvent whatever we want, notions like that. And so everything from the famous Tatlin sculpture for the Communist International (tragically never actually built) to ordinary flatware 
was conceived or reconceived. The idea was that revolution would be imbued in the very pores of society. And this meant giving every citizen the opportunity to be engaged.

What do you see now, though? Every kind of consumer good out there expresses some kind of aesthetic philosophy. A hundred years ago there wasn't as much concern for how pretty or aesthetically interesting the items owned by the working class might be. The boom in consumerism has changed that. And so the Tatlins of yesterday are finding themselves working for Ikea today, regardless of their political ideals. Capitalism is a very flexible system: it has learned the art of what the Situationists described as detournement quite well. And so while the incorporation of aesthetics into everyday objects during the Russian Revolution were meant to express the liberation that gave rise to them, today the aesthetics of consumer goods are meant to distract, conceal, and encourage you to forget the exploitation that made them. That's perhaps an overly specific example, but I think it's illustrative.

More to the point perhaps is how artists who make their living off their own aesthetic expression-those lucky few who can make a living off their own music or painting and so on-are forced to rely on the patronage of the rich. And if you're making art that seeks to explode preconceived notions of what is good or acceptable in art itself, then you're not getting hired by lkea. You have to beg for people with the funds to buy your art to recognize your unique "genius." This can reinforce the kind of intrinsic elitism in an avant-garde project that I described earlier. It also shapes the kind of art you make, but in a different way than if you're working in industrial design or something like that. So that's what I think we can broadly describe as the avant-garde being the purview of the elite.

It doesn't have to be that way, though, and that's what Ho seems to have understood. I can't speak to his experience with other artists across the board. But the way he described his time in the League of Revolutionary Struggle is, I think, instructive in how he viewed the role and substance of the avant-garde. The League was one of the countless Maoist groups to come together in the 1970s out of the generalized struggle around racial justice that had rocked the United States. It had an artistic orientation that was admirable in many ways: a few big names from the Black Arts Movement and other racial pride milieus were attracted to the LRS, including Amiri Baraka. And so a lot of the art created in connection with the group sought to highlight the indigenous sounds of these various cultures across the developing or colonial worlds.

The problem, hear Ho tell it, was that there was almost no innovation to these sounds even as they were being highlighted out of an impulse of international solidarity. In some ways, the cultural view of the LRS was one that saw itself as highlighting forms of popular art at the expense of a supposedly elitist avant-garde. This difference is nothing new: it's been a debate in the left since at least the 1930's in the debates between Georg Lukacs and Ernst Bloch. The former thought that the perceived elitism of Expressionism made it inherently reactionary and championed an argument that art should truthfully show reality. The latter argued that Expressionism was a legitimate response to a decaying order and saw a genuine utopianism in it. I happen to agree much more with Bloch's arguments than with Lukacs's, which probably explains why I find Fred Ho such a fascinating and brilliant artist. Ho wholeheartedly rejected the notion that all art has to be literal or static and also believed that the avant-garde can ignite the imaginations of the masses. The problem with a rejection of the avant-garde in favor of popular-for-popular's-sake is it becomes a self-fulfilling prophecy: the cultural horizons of workers you're trying to reach may be broadened, but eventually they will hit a limit because you're wary of exposing them to avant-garde art, and as a result the perception of the avant-garde as elitist remains in place.

How did Ho seek to counter this? He did it in a very interesting way. First is the mixing of these indigenous sounds with arrangements commonly thought of as jazz that I mentioned above. But also what does it mean for you to all of a sudden do a version of the theme from Spiderman or "In-A-Gadda-Da-Vida" in that ouevre? These are items of pop culture being reinvented in a way we haven't heard before-being made "avant-garde." He did the same thing when he injected tropes and influences from Japanese manga and Bruce Lee films. When it was successfully done, it allowed us to see popular art in new and subversive lights. It's that same irreverence that still somehow manages to show respect to the original genres because it allows you to see it all as new again. The popular becomes avantgarde and the avant-garde becomes popular. Again, all sorts of questions arise about whether it's successful, but wow!

GS: In your review of Yellow Power, Yellow Soul, a collection of essays on Ho's work, you write that "What one takes from the book is a sense not just of the importance of Ho's work, but of how a new, vital, politically engaged, even dialectical avant-garde art might look." What, in your estimation, does that look like? In what ways do you see that in Ho's music?

AB: Maynard Solomon described art's utopian impulse as being an imagination of the future by reference to the past: it's dialectical. What does it mean for art to both look backward and forward at the same time? When I try to answer 
this, I think of Walter Benjamin. Benjamin was fascinated with the way in which the most advanced technology could drive artistic expression forward, but he also had a serious interest in the romantic, the primitive, and the mystical. His "Theses On the Philosophy of History" revolved around the notion of a past that isn't really past because it has yet to be redeemed. So the rather perfect irony I think he was getting at is that in order to have a truly radical voice in culture, you have to in turn give a voice to those elements in our culture which capitalism would like pushed to the side or faded into distant memory. This may sound counter-intuitive, but if you think about it, so much of modernism was about amplifying these voices and placing them at the forefront of an evolving cultural landscape. Think about the folk revival of the 1930's. Jazz and blues too were also about taking the sounds of the African diaspora and placing them front-and-center onstage as they were made new.

Of course, this isn't the whole story of modernism or even just its political side. There were those like the Futurists who consciously sought to break with what they considered to be the old and backward. So I don't want people to think that I'm saying this is the whole story. But it's certainly a big part of the story. And there are plenty who would argue that the extreme abstraction of some of these hyper-modern art movements also took a cue from the more esoteric strands of romanticism. That's the catch of this approach, I think: that the most progressive and dynamic elements of old romanticism, folk cultures, etc, are actually not just preserved, but accentuated by this take on modernism. It's at one turn dialectical; at another it's thoroughly democratic, taking into account the ways that capitalism deliberately under-develops large sections of the population it needs to exploit. If one thinks about it, the job of a radical vanguard and that of a politically engaged avant-garde are quite similar (and yes, the two terms mean basically the same thing): to amplify the voices, the wants, urges, and to activate the imaginations of those that the system leaves behind, but not just in a way that's rote or static. Aesthetically speaking, this impulse is the most effective when it seeks to create new frameworks, new logics, new ways of looking at the world that explode the dominant viewpoints of how society should work.

Ho's work, I think, reflected this in some of the ways I've described in my articles on him. He very consciously focused on incorporating folk art and music from nations that have been oppressed or colonized, or maybe have just been neglected by the attention of the Western music industry. Think of the Filipino randallia or Chinese folk songs. He incorporated all of this into arrangements that we undoubtedly understand as jazz, and good jazz at that. Then, of course, there's the inclusion of tropes from martial arts films, sci-fi, time travel, all the rest. When its done successfully in Ho's work, it's not just a bunch of disparate elements thrown into a big aesthetic jumble; it creates a new narrative, a sense that those elements in society most frowned upon, most neglected and abused, may actually be the engine of a new world culture: one that is intrinsically internationalist and inclusive, but goes beyond liberal notions of multiculturalism. It's a far cry from these orientalist notions of "world music," because it insisted that these cultures he incorporated into his compositions can have a life of their own, their own evolutionary paths that they can easily interweave with others without being appropriated or frozen in time.

GS: Can you elaborate on your claim that "Neoliberalism's assault on the cultural resources of working and oppressed people, combined with the tight consolidation of the record industry, has left precious little space for discussions of aesthetic liberation"? Can you give us a more specific sense of how this process has worked?

AB: Neoliberalism is all about depriving working people of anything that could be a locus for resistance. I agree with Sam Gindin when he says that the neoliberal ethos is basically "capitalism getting its groove back." So what little social safety net that ever existed in the United States has been under attack for a long time. You can perhaps see it more easily in European countries that have had more of a tradition of social democracy, if only because there's more to actually attack, but it's happened in North America too. When you are looking to lower the living standards of working people, you don't just go after their wages or benefits or actual working conditions; you go after the social wage. That means the public transit they take to work can be privatized, its fares raised, the number of buses on the street at any given time can be lowered.

I'd argue in the United States that this is the most pronounced in the war on public education: the push to slash public schools down to the bone and wherever possible replace them with privately-run charter schools. That also may be the easiest example to illustrate how spaces for aesthetic liberation are similarly squeezed. Arts and music programs are normally the first to be eliminated when a school or district's budget needs to be cut. This of course has an awful effect on a child's learning: it's well-known that art and music are crucial for developing critical thinking, non-linear thinking, and all the rest. But you're also basically cutting kids off from a key avenue of self-expression. How many potentially revolutionary artists are missing their chance to discover that part of themselves right now? What massive changes in the art world might transpire if we gave these kids the tools to discover themselves? How many of them are being denied that? It's quite a heartbreaking state of affairs if you really think on it. 
It's true for so many other areas that we would call cultural resources. There are fewer libraries now, fewer community art programs. It's more prohibitively expensive to go to art school than it was thirty years ago. I'm of the mind that even if you're endeavoring to make art that breaks the mold of all art that came before, you still need to have a basic mastery or at least knowledge of what came before. When you deny people the chance to gain that mastery, you damage the future of art and human creativity itself.

This isn't even taking into account the added complicators of racism, queerphobia, or misogyny, which all exacerbate the basically exploitative dynamics already at play. If arts spaces aren't safe spaces, spaces that can take into account differences of race, gender identity, and sexual orientation while also fostering solidarity, then we're also limiting the possibility of artists from oppressed communities finding their voices or reaching an audience with whom their art can resonate. Our schools are so anemically funded that teachers-try though they might, and very noblydon't have the resources to fully transform the art classrooms into those types of spaces. And our institutions of higher learning-be it Columbia or CalArts-have shown themselves to be uninterested in fostering safe space for female students, queer students, gender-nonconforming students, or students of colour. Again, we can see clearly through the writings of people like Henry Giroux in which this has been tied to neoliberal education reforms from pre$\mathrm{K}$ all the way up through the university.

So even at the most basic level, the deck is already stacked against the flourishing of a modern avant-garde. That's not to say it can't happen, or that it's not already happening in many localities across the globe, but the space for it to flourish and reach more people, to really shake things up, is much narrower. The twist is that this therefore makes a new avant-garde so much more necessary. Without public resources that artists and potential artists might use to support their work, the only avenues left are private ones: corporations willing to sponsor galleries, record companies or concert promoters. These are privately run. Supporters of the free market might say that this ensures a free exchange of ideas, but I believe that the allowance of the market to predominate over art merely imposes another set of rules and restrictions over art. As a record executive, when you're looking to turn as big a profit as possible, you're less willing to take a risk on the unorthodox.

This isn't to say that the present conditions of neoliberalism make it impossible for avant-garde art to take root. In fact, as I believe I've written in one of my articles about Ho, the irony is that the need of politically engaged avantgarde art is accentuated precisely because neoliberalism is so culturally narrow. What it is to say is that the obstacles placed in front of such an avant-garde, in front of what we might term "aesthetic liberation," are quite formidable. The challenge for us-and it's a big one-is to try to husband what few resources we do have into independent spaces for a new, politically engaged avant-garde to take root and flourish. The radical pop-up galleries, the DIY music venues, the independent theaters: we need to treasure these spaces_few and far between though they may be-and really build them up so that they can be what they deserve to be.

GS: One argument you make that really resonates with me-and that I think clearly applies to Canada as well-is that "one of the contemporary American left's greatest weaknesses is its skittishness regarding the concept of utopia. The ways in which neoliberalism has cut us off from the belief that humans can collectively build a better world goes hand in hand with the sidelining and co-optation of the avant-garde. It's hardly a coincidence that these projects have been written off as fanciful and elitist." What do you think is the relationship between the avant-garde, particularly improvised jazz, and the utopian? How and why did both of these come to be regarded as elitist?

AB: There are a lot of different angles to play at with how improvised jazz is utopian. There's been plenty of writing on the inherent democracy that came to be reinjected to jazz during the bebop years: when the large orchestras were stripped down to four or five musicians with only the most basic elements at their disposal, and when they simply said yes to the basic arrangement and theme of the song, but let each member "do their thing," it expressed a democratic way of doing things. I can see a certain truth with that (though there have been plenty of jazz musicians who are notorious tyrants too-right off the top of my head, Miles Davis and Charles Mingus come to mind). I think there's something deeper that l've encountered less of in reading about jazz and speaking with the artists: namely that when you "let the moment take you" so to speak, when you've internalized the rhythm and key and all the other basic minimums that a band has to agree with in order for a piece to work, and yet simultaneously allowing yourself to go on an unpredictable riff-a riff that maybe even you have no idea how it will end up-that's when the utopia starts to come out. In that moment, you are both organically and seamlessly rooted in your aural surroundings and reinventing those surroundings on the fly. It's a freeing experience-and it doesn't just apply to jazz.

This is why some avant-garde movements have been interested in one way or another with psychology. Art can be an opportunity to give voice to all those thoughts and urges and emotions that are silenced in a society as thoroughly alienated as ours: it's precisely why art therapy is a legitimate thing. None of us are raised to think really creatively about the world. We're raised to work, to sacrifice our minds and our bodies to menial tasks, the fruit of which we'll 
never really see. It's a completely inhumane state of affairs, and it's compounded by issues of gender oppression, racial oppression, all the rest. But what makes us human is our ability to create, to not just adapt to our surroundings, but change them. So to have this very human nature denied of us is basically to deny anything that can make labor creative or interesting for us: it's what Marx talks about when he describes all labor "losing its charm" for the worker. This is to say nothing of all the things that we feel as people that are looked down on or discouraged in contemporary society. So the human condition right now is one of severe alienation and repression. Art can be a channel for that, and can give us glimpses of a much more liberated way of life. It's only a glimpse, and it's a fractured glimpse at that, but it's still quite potent. Naturally, with everything l've mentioned above, there is a tendency toward the commodification of that which we would call artistic or creative labor, so that problematizes things even further. Capitalism is a very slippery system and has a great capability to make that which was once freeing and subversive into something tame that can work for the sake of profit. So the trick of an avant-garde is to provide an alternative free from the fetters of commodification. An artistic avant-garde that is avowedly political one would think would be doubly conscious of this.

How do the avant-garde and jazz become conceived of as elitist? Part of that l've again touched on above. The process of commodification in the arts always encounters art that won't be commodified as easily, or at all. For example, you can turn punk rock from something rebellious into a fashion you can buy at Hot Topic by pouring millions into promoting Fall Out Boy and such sound-alikes as What is Punk. But that doesn't answer what you do with a band like Refused, who during their whole career went out of their way to make very intricate and interesting music that shattered the very mold of what it means to be punk. What do you do with those kinds of artists? Part of the problem is already solved by the fact that the sound produced by a Refused as opposed to a Fall Out Boy is much less predictable, more challenging: it demands engagement rather than passive acceptance, it doesn't correspond to the simple verse-chorus-verse-chorus pattern that we expect from punk rock. So already the audience is going to be harder to reach. This is always an obstacle for an avant-garde movement that wants to get its ideas to a wider audience.

But this can be easily reinforced by all sorts of conceptions that fly about regarding avant-garde movements-or even movements that don't readily conform to notions of what art "should be." What seems to me the most insidious is this notion that "ordinary people" (however, that category is qualified: "real Americans," "most folks," etc.) don't want to engage with "that kind of art," which is itself an incredibly elitist way to conceive of ordinary people if you think about it, but nonetheless it stands. It's precisely how broadcasting companies, television networks, or record labels can make the claim that "they're only giving people what they want." That's the rationale from which they're working. Fredric Jameson, when he talks about post-modernism as the cultural logic of late capitalism, is right on the money when he points out that this crude, manipulative kind of anti-elitism covers for a very real rule by very real elites. To be brief, the message it sends to the audience and populace is either that the art in question isn't within the reach of the average person's creativity, or that it's somehow degenerate and therefore not worth trying to create in the first place.

Both of these have happened to jazz at one time or another. The current place it occupies is both interesting and depressing. Of course, it hasn't been the most popular form of American music since at least the advent of rock and roll, but it managed to keep up a flourishing avant-garde scene. There are still plenty of avant-garde and experimental jazz musicians, but they're not at the epicenter of the genre the way Coltrane or Mingus or Sun Ra were back in their day. They don't have the clout needed to push the genre forward the way those artists did. Jazz has taken its place as "respectable" American art. That Wynton Marsalis is probably the genre's best-known spokesperson-a spokesperson who regards the out-there experimentation of free jazz as very much lesser-says quite a bit. So it's something of a schizophrenic place to occupy: jazz has been tamed, made safe for consumption, even as it's been sidelined in the popular consciousness, while the experimentation that once made it such a cultural juggernaut is explained away somehow.

GS: You end your review of Yellow Power, Yellow Soul by saying that "Ho's work is a connection to the vibrant and wonderful tradition of the radical imagination.[. . . T] here can be little doubt that [Ho has] left important lessons for a nascent radical culture to grab hold of." Can you say more about the tradition of the radical imagination and Ho's place in that? What would you say are some of the important lessons that Ho has left for a nascent radical culture?

AB: Fred Ho wasn't just a unique musician. He certainly was that, no question about it, but I think he was also part of a through-line, a tradition of radical creativity that really is too broad to sum up in one answer. That tradition has in the past been a very vibrant one with countless facets and schools of thought, sometimes with very strong disagreements as to what might constitute a radical aesthetic practice. Ho saw himself as standing in that tradition. I'm sure there are people out there who also see themselves as standing in that tradition, but would take strong issue as to the aesthetic 
choices he made. That's fine. I think when it comes to questions of art and culture, we'll suffer if we don't allow for those differences.

The fact is that really ever since there has been such a thing as radicalism, there's been an imagination to complement it. The left wing of the French Revolution-which is where we get the whole idea of left vs. right in politics-was tremendously imaginative. It had to be: it was endeavoring in building something that had never existed before. That's the point: we can and should theorize and be materialist in our assessments, and take our education seriously. But at a certain point, fighting for a better world has to take that leap into the imaginary precisely so that it can make fantasy into reality. There are a lot of things that make for a stronger radical left, but it's undeniable that when such movements have been the strongest, that imagination has also found itself able to flourish.

That's one of the things in which we are left wanting. What's lacking in contemporary "political music" is the desire for utopia, and I think this reflects a deeper categorical mistake on the part of today's fractured (though undeniably reviving) radical left. It's an error that tends to look at art and politics as corresponding to the same laws-they don't. They interact and can constitute each other, as I said above, but they are in essence different things. A song can't serve the same purpose as a polemic or piece of political economy or a speech against imperialism. There have been plenty of attempts to breed the two together, some interesting and some failures, but the interesting ones have been interesting precisely because of the incompatibility of the two.

What you hear far more often is the expectation that musicians and artists somehow project a perfect set of politics into their work ("it doesn't offer a solution," etc.), and to be honest, I can't think of anything more boring. Asking for political clarity from your art is like being mad at your vacuum cleaner for not making coffee. The two serve entirely different purposes, and the flattening of the two sells art short in its own particular strengths and modes, which are categorically different from theory and all the rest. Art should make you feel and imagine in ways that straightforwardly relayed concepts don't. When we forget this, when we muddy the delineation between the two, then we cut ourselves off from what it means to have a political understanding of art.

There's a deeper layer to the onion: What is it that has muddied this water? I think it's thirty-five years of defeat quite frankly. We've been so preoccupied with trying to regain our previous strength, to get back to where we were, that we've forgotten where we're headed. We've lost sight in some ways of the ultimate and totalistic goal: a fully liberated society. Our theories, our strategies, our tactics and ways of explaining the world, have to be clear-headed and sober. This is certainly true; otherwise, they're of no use. But being utopian? That's art's strong point: it's where we can allow ourselves to imagine and fantasize and strengthen the parts of our creativity that get systematically neglected and atrophied under capitalism.

If that's all that Fred Ho leaves for us to learn from, then I think he will have left a safe and wonderful legacy. To be honest, he's left us a lot more, but the need for utopia is probably the most important from a radical artistic standpoint in my opinion. He wasn't afraid to let propaganda live in his music: he never shied away from letting you know what he believed. But first and foremost, his sounds and compositions were attempts at creating a new logic fundamentally different from and subversive to what we're told. People will roll their eyes and call it idealistic, but that's kind of the point: if our art doesn't allow for our dreams to be exalted in some way, we're doing it wrong.

\section{Notes}

1 Just a few of the many cross-disciplinary works that contribute to post-Cold War conversations about the radical imagination are Dionne Brand's poetry collections Inventory and Thirsty, James Cairns and Alan Sears' The Democratic Imagination, Sam Gindin's article "Art in the Age of Fatalism" in Jacobin, Max Haiven and Alex Khasnabish's The Radical Imagination, Fredric Jameson's Archaeologies of the Future, and Larissa Lai's novel Salt Fish Girl, as well as the article cited in this introduction.

${ }^{2}$ For a further discussion of the relationships between improvised jazz and utopia, see my ICASP think piece: "Tunes from Brainville: Improvised Jazz and/as Utopia." Improvisation, Community, and Social Practice (13 February 2014).

${ }^{3}$ Interview conducted via email.

4 "Allopathic medicine" is a term that advocates of alternative medicine use to describe mainstream medical approaches. 


\section{Works Cited}

Billet, Alexander. "Change the People." Rev. of Yellow Power, Yellow Soul: The Radical Art of Fred Ho, ed. Tamara Roberts and Roger Buckley. Jacobin 14 (2014): 62-66. Print.

---. “Fred Ho's Far-Out, Radical Journey." Jacobin 21 Apr. 2014. Web. 5 July 2015.

<https://www.jacobinmag.com/2014/04/fred-hos-far-out-radical-journey\%E2\%80\%A8/>.

Ho, Fred. Diary of a Radical Cancer Warrior. New York: Skyhorse Publishing, 2011. Print.

Wright, Erik Olin. "Real Utopias." Contexts 10.2 (2011): 36-42. Print. 